DOI: $10.34185 / 1991-7848.2018 .01 .05$

УДК 669.162.24:621.928.2(043)

А.М. Криворучко, С.В. Кадильников

\title{
ДИНАМИЧЕСКАЯ МОДЕЛЬ ВИБРОПРЕССОВОЙ УСТАНОВКИ
}

\begin{abstract}
Вибрационные процессы широко используются в различных областях техники для получения, так называемых, полезных эффектов. Для обработки металлов давлением (ОМД) эти эффекты связаны в первую очередь с получением готовой металлургической продукции с улучшенными структурночувствительными свойствами металла, качеством поверхности, низким энергопотреблением при проведении технологических операций. Целью работы является построение динамической схемы прессовой установки и обоснование параметров синхронизации вибровозбудителей. Приведены результаты модельных исследований вибропрессовой установки прерывистого характера деформирования обрабатываемого металла. Исследованы вопросы синхронизации вращения роторов вибровозбудителей. Полученные данные могут быть использованы при разработке перспективных образцов оборудования, задействованных в производстве металлургической продукции с улучшенными структурно-чувствительными свойствами металла.

Ключевые слова: вибрационный процесс, рабочий орган, прессовая установка, вибровозбудитель, вибростол, инерционный элемент.
\end{abstract}

\section{Постановка проблемы}

В настоящее время вибрационные процессы широко используются в различных областях техники для получения, так называемых, полезных эффектов. Для обработки металлов давлением (ОМД) эти эффекты связаны в первую очередь с получением готовой металлургической продукции с улучшенными структурно-чувствительными свойствами металла, качеством поверхности, низким энергопотреблением при проведении технологических операций.

Прерывистый характер деформирования при вибрации рабочих органов машин или обрабатываемого металла приводит к ряду положительных эффектов, таких как уменьшение сил контактного трения, снижение сопротивления деформации, эффективного значения деформирующей силы и работы деформации, дает возможность осуществлять поочередное деформирование полосы несколькими инструментами, вибрирующими со сдвигом по фазе. Все это создает реальные предпосылки для интенсификации процессов штамповки, волочения, прокатки, осуществляемых с применением колебаний различных диапазонов частот.

\section{Анализ последних исследований и публикаций}

Вопросы использования ультразвука при обработке металлов давлением широко освящены в работах [1-4]. Основные факторы вибрационных процессов с использованием низкочастотных механических колебаний, снижающие рабочие напряжения и силы при обработке металлов давлением, рассмотрены в [5].

Однако в перечисленных работах не затронуты вопросы динамики вибрационных процессов в рабочих органах машин и технологичности различных типов вибрационных устройств, применяемых для реализации процессов ОМД. Между тем проблемы, связанные с выбором динамических систем вибрирования, являются ключевыми при реализации процессов ОМД. От того, насколько применяемые вибрационные возбудители по своим техническим и эксплуатационным характеристикам соответствуют требованиям определенной динамической схемы и режимам процессов вибрационного деформирования, зависят эффект, получаемый от всей технологической операции ОМД.

(C) Криворучко А.М., Кадильников С.В., 2018 


\section{Цель исследования}

Целью настоящей работы является построение динамической схемы прессовой установки и обоснование параметров синхронизации вибровозбудителей.

\section{Основной материал исследования}

Основываясь на практических наблюдениях, можно сформулировать основные требования, которым должны соответствовать оптимальные вибровозбудители для технологических целей ОМД - создания колебаний в рабочих органах и обрабатываемом металле:

- мощность, достаточная для выполнения данной конкретной технологической операции;

- наименьшие габаритные размеры при заданной мощности, т.е. наибольшая удельная мощность;

- простая регулировка по частоте и амплитуде задаваемых вибраций в пределах, определяемых технологическими требованиями;

- долговечность при работе в экстремальных условиях (повышенная температура);

- стабильность частотных характеристик в пределах установленного допуска при изменении массы и силы нагружения;

- плавная безударная работа без лишних шумов;

- несложная компоновка с рабочим органом с оптимальной массой колеблющихся частей;

- наименьшее время вхождения в заданный режим работы;

- простота, несложность в изготовлении, экономичность;

- использование стандартных источников подводимой мощности.

В технологических операциях прессования в качестве возбудителей колебаний заготовок, а также непосредственно рабочих органов машин, используются дебалансные механические вибровозбудители, которые часто называют инерционными. В этих возбудителях возмущающая сила создается вследствие вращения одной неуравновешенной массы в одном и том же направлении и изменяется только по величине.

Ввиду того, что в прессовании применяются достаточно металлоемкие машины, то для получения вибрационных эффектов берется не один, а несколько вибровозбудителей. Это связано с тем, что для сосредоточивания возмущающей силы по вибрирующему органу значительных размеров использование одного мощного возбудителя недостаточно из-за затухающих эффектов на вибрирующей поверхности. Более рациональным является применение нескольких маломощных вибровозбудителей по всему рабочему органу машины. Применение двух (или любого четного числа) дебалансных возбудителей, роторы которых вращаются с одинаковой угловой скоростью в противоположных направлениях, позволяет получить возмущающую силу постоянного направления. Обычно на практике в связи с этим возникает проблема в синхронизации вращения роторов вибровозбудителей, т.е. имеет место проблема вибрационной поддержки вращения роторов.

Рассмотрим вибрационный стол прессовой установки в виде системы, схематически представленной на рис.1. Несущее тело $B_{0}$ - вибростол считается твердым телом, способным совершать малые плоско-параллельные колебания. Несущее тело $B_{0}$ связано с неподвижным основанием прессовой установки системой демпфирующих элементов 1. На вибростоле размещено $n$ дебалансных вибровозбудителей 2. Оси вибровозбудителей считаются перпендикулярными плоскости, параллельно которой происходит движение тела $B_{0}$. 


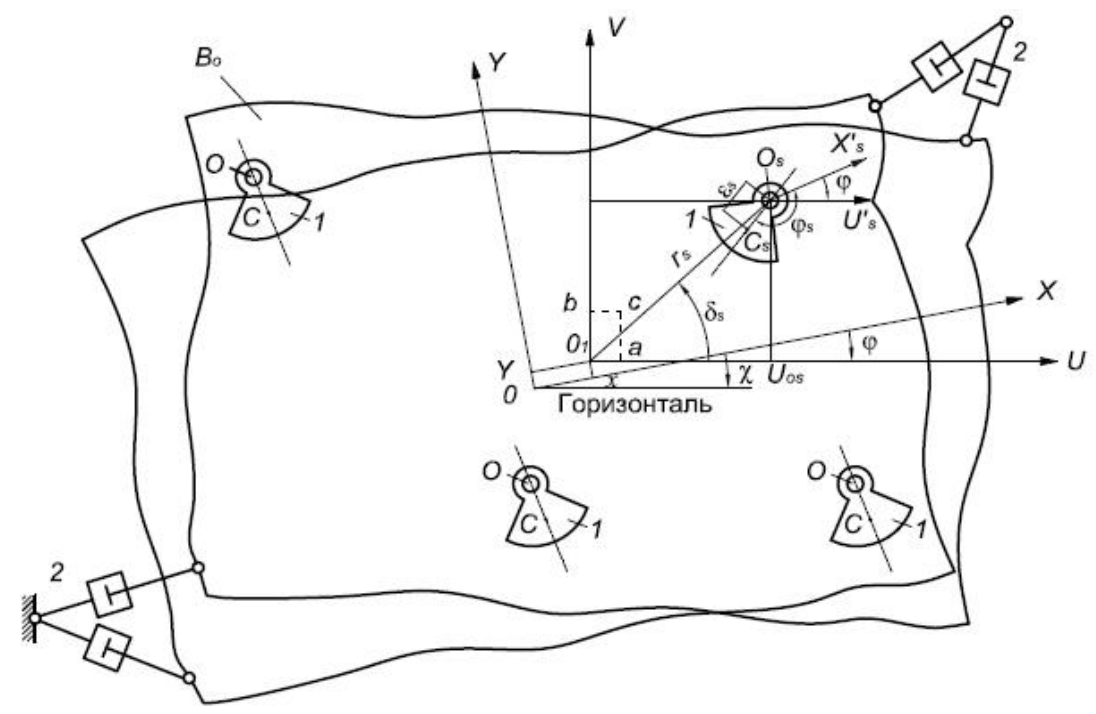

Рисунок 1 - Схема вибростола для прессования заготовок

Пусть $u O_{1} v$ - система осей, жестко связанных с несущим телом $B_{0}$, начало координат $O_{1}$ выбрано в центре тяжести так называемого вспомогательного тела, т.е. тела, получающегося из $B_{0}$, если присоединить к нему массы всех инерционных элементов. Пусть $X O Y$ - неподвижная система осей, с которой совпадают оси $u O_{1} v$ в положении статического равновесия системы. Предполагается, что потенциальная энергия инерционных элементов в данной системе не учитывается ввиду малости составляющей их веса по отношению к весу рабочего органа.

За обобщенные координаты несущего тела $B_{0}$ примем координаты $x$ и $у$ точки $O_{1}$ в системе XOY и угол поворота тела $\varphi$, отсчитываемый по ходу часовой стрелки. Так же отсчитываются от неподвижной оси $O X$ и углы поворота $\varphi_{s}$ инерционных элементов вибровозбудителей.

Воспользуемся уравнениями Лагранжа второго рода [6]:

$$
\begin{gathered}
M x+c_{x} x+c_{x \varphi} \varphi=\sum_{s=1}^{n} m_{s} \cdot \varepsilon_{s} \cdot \omega^{2} \cos \left(\omega t+\alpha_{s}\right) ; \\
M y+c_{y} y+c_{y \varphi} \varphi=-\sum_{s=1}^{n} m_{s} \cdot \varepsilon_{s} \cdot \omega^{2} \cdot \delta_{s} \cdot \sin \left(\omega t+\alpha_{s}\right) ; \\
\mathcal{I} \varphi+c_{\varphi} \varphi+c_{x \varphi} x+c_{y \varphi} y=\sum_{s=1}^{n} m_{s} \cdot \varepsilon_{s} \cdot \omega^{2} \cdot \delta_{s} \cdot r_{s} \cdot \sin \left(\omega t+\alpha_{s}\right),
\end{gathered}
$$

где $m_{s}, \mathcal{I}_{s}, \varepsilon_{s}$ - соответственно массы, приведенные моменты инерции и эксцентриситеты возбудителей; $\delta_{s}$ - полярные координаты осей возбудителя; $M, \mathcal{I}$ - масса и момент инерции вспомогательного тела; $c_{x}, c_{y}, c_{\varphi}, c_{x \varphi}, c_{y \varphi}-$ квазиупругие коэффициенты; $\omega$ - собственная частота колебаний системы; $\alpha_{s}$-начальная фаза колебаний системы; $\mathrm{r}_{\mathrm{s}}-$ полярные координаты осей возбудителя.

Решение системы (1) позволяют для заданной частоты вынуждающей силы выбирать приемлемые для технологического процесса прессования величины обобщенных координат $x, y, \varphi$. При этом возникает проблема исследования устойчивости установившихся режимов синхронного движения вибровозбудителей, а также процессов установления таких режимов (синхронизации). С этой целью к уравнениям переходных процессов (1) следует применять асимптотические методы, в частности стробоскопический метод [7]. Стробоскопическая система, соответствующая решениям (1) имеет вид: 


$$
\dot{X}=X(x, y, t, \mu) ; \dot{Y}=Y(x, y, t, \mu),
$$

где $\mu$ - малый параметр ( $\mu \geq 0)$.

Относительно этой системы будем предполагать, что она близка к линейной автономной системе со степенью близости $\mu$, а параметры $x, y$ являются $\mathrm{T}$-периодическими функциями временного параметра $t$.

Стробоскопические смещения за период $T$ произвольной точки системы в конечноразностной форме имеют вид:

$$
\frac{d \rho}{d \tau}=\mu L\left(\rho_{0}, \varphi_{0}\right) ; \frac{d \varphi}{d \tau}=\mu F\left(\rho_{0}, \varphi_{0}\right)
$$

Здесь:

$$
\begin{aligned}
& L\left(\rho_{0}, \varphi_{0}\right)=\frac{1}{\mathrm{~T}} \int_{0}^{T} f\left(\rho_{0}, \varphi_{0}-t, t\right) d t \\
& F\left(\rho_{0}, \varphi_{0}\right)=\frac{1}{\mathrm{~T}} \int_{0}^{T} g\left(\rho_{0}, \varphi_{0}-t, t\right) d t,
\end{aligned}
$$

где $f, g$-периодические функции временного параметра $\tau ; \rho_{0}, \varphi_{0}$ - постоянные, определяемые начальными условиями, и отвечающие равномерному движению системы по ходу часовой стрелки по окружности радиуса $\rho_{0}$.

Решения дифференциальных уравнений (1) позволяют в первом приближении найти начальные углы поворота инерционных элементов, а также их оптимальное расположение на несущем теле.

\section{Выводы}

Исследования уравнений движения вибрационной прессовой установки позволяют выбрать оптимальное число вибровозбудителей.

При разбросе значений обобщенных параметров на 1-5\% нецелесообразно увеличение числа вибровозбудителей.

Для четного числа инерционных вибровозбудителей, расположенных на мягко амортизированном твердом теле, совершающим плоские колебания, целесообразно симметричное расположение инерционных элементов.

\section{ЛИТЕРАТУРА}

1. Резников Ю.Н. Волочение металлов с наложением ультразвуковых колебаний.- В кн.: Формоизменение при обработке металлов давлением. Ростов н/Д: РИСХМ, 1970, С.127-133.

2. Северденко В.П., Клубович В.В., Степаненко А.В. Прокатка и волочение с ультразвуком. Минск: Наука и техника, 1970, 228 с.

3. Северденко В.П., Клубович В.В., Степаненко А.В. Обработка металлов давлением с ультразвуком. Минск: Наука и техника, 1973, 228 с.

4. Харитонович М.В., Эскин Г.И. Ультразвук в процессах пластической деформации металлов и сплавов. М.: ВИЛС, 1970, 110 с.

5. Клименко В.М., Шаповал В.Н. Вибрационная обработка металлов давлением. К.: Техника, 1977, 128 с.

6. Блехман И.И. Синхронизация в природе и технике. М.: Наука, 1981.-352с.

7. Математические методы анализа нелинейных колебательных систем/ Митропольский Ю.А., Мосеенков Б.И., Самойленко А.М., Блехман И.И., Неймарк Ю.И. - В кН.: Вибрации в технике (справочник). Т.2. Колебания нелинейных механических систем. М.: Машиностроение, 1979.- 324 с.

\section{REFERENCES}

1. Reznikov Yu.N. Volochenie metallov s nalozheniem ultrazvukovyih kolebaniy.- V kn.: Formoizmenenie pri obrabotke metallov davleniem. Rostov n/D: RISHM, 1970, S.127-133. 
2. Severdenko V.P., Klubovich V.V., Stepanenko A.V. Prokatka i volochenie s ultrazvukom. Minsk: Nauka i tehnika, 1970, $228 \mathrm{~s}$.

3. Severdenko V.P., Klubovich V.V., Stepanenko A.V. Obrabotka metallov davleniem s ultrazvukom. Minsk: Nauka i tehnika, 1973, $228 \mathrm{s.}$

4. Haritonovich M.V., Eskin G.I. Ultrazvuk v protsessah plasticheskoy deformatsii metallov i splavov. M.: VILS, 1970, $110 \mathrm{~s}$.

5. Klimenko V.M., Shapoval V.N. Vibratsionnaya obrabotka metallov davleniem. K.: Tehnika, 1977, $128 \mathrm{s.}$

6. Blehman I.I. Sinhronizatsiya v prirode i tehnike. M.: Nauka, 1981.-352s.

7. Matematicheskie metodyi analiza nelineynyih kolebatelnyih sistem/ Mitropolskiy Yu.A., Moseenkov B.I., Samoylenko A.M., Blehman I.I., Neymark Yu.I. - V kN.: Vibratsii v tehnike (spravochnik). T.2. Kolebaniya nelineynyih mehanicheskih sistem. M.: Mashinostroenie, 1979.- 324 s.

Received 23.01.18

\section{DYNAMIC MODEL OF VIBROPRESS APPARATUS}

At present, vibration processes are widely used in various fields of technology to produce socalled beneficial effects. For the treatment of metals by pressure (OMD), these effects are primarily associated with the production of finished metallurgical products with improved structurallysensitive metal properties, surface quality, and low energy consumption during technological operations. The purpose of this work is to construct a dynamic scheme of a press installation and justify the synchronization parameters of exciters. The results of model studies of a vibro-press installation of the discontinuous nature of deformation of the metal being processed are presented. The problems of synchronization of rotation of rotors of exciters are investigated. The data obtained can be used to develop promising models of equipment involved in the production of metallurgical products with improved structural-sensitive properties of the metal.

Key words: vibration process, working organ, press installation, vibrator, vibration table, inertial element.

\section{ДИНАМІЧНА МОДЕЛЬ ВІБРОПРЕСОВОЇ УСТАНОВКИ}

Наведені результати модельних досліджень вібропресової установки переривчастого характеру деформування металу, що оброблюється. Досліджені питання сінхронизації обертання роторів віброзбуджувачів. Дані, що отримані, можуть бути використані при розробці перспективних зразків обладнання, що використовуються при виробництві металургійної продукції з покращеними структурно-чутливими властивостями металу.

Ключові слова: вибрационный процес, робочий орган, прессовая установка, вибровозбудитель, вибростол, інерційний елемент.

Криворучко Александр Михайлович - к.т.н., доцент, кафедра технологии машиностроения, Национальная металлургическая академия Украины.

Krivoruchko Alexander - Candidate of Technical Sciences, Associate Professor, Department of Mechanical Engineering Technology, National Metallurgical Academy of Ukraine.

Кадильников Святослав Витальевич - аспирант, кафедра технологического проектирования, Национальная металлургическая академия Украины.

Kadilnikov Svyatoslav - Postgraduate Student, Department of Technological Design, National Metallurgical Academy of Ukraine. 